\title{
EDUCAÇÃO AMBIENTAL EM MUSEUS DE CIÊNCIA: DIÁLOGOS, PRÁTICAS E CONCEPÇÕES
}

\author{
Gustavo Costa Meyer ${ }^{1}$ \\ Guilherme Costa Meyer
}

Resumo: O principal objetivo deste trabalho foi a problematização de quais aspectos possui a educação ambiental concebida e praticada em museus de ciência, tendo-se em vista a heterogeneidade de visões que cercam a questão ambiental, com as devidas posições político-ideológicas que sustentam tal entendimento. Para tal análise, utilizou-se, principalmente, de referenciais teóricos que tratam: da comunicação e divulgação científica em museus, da ecologia de saberes, da crise cognitiva e da necessidade do diálogo de saberes, e da concepção de educação ambiental crítica. Avaliou-se que a forma de educação ambiental que prevalece em alguns museus de ciência é fragmentada, reducionista e a-histórica, com abordagens pedagógicas ligadas, preponderantemente, a aspectos das ciências naturais.

Palavras-chave: Museus; Educação Ambiental; Educação Científica.

\section{Educação Ambiental e Museus de Ciência: primeiros aspectos}

O objetivo de apresentar aos indivíduos instrumentos que possibilitem uma análise crítica dos aspectos inerentes à ciência em sua relação com o meio ambiente e a sociedade (tais como sua fragmentação, sua relação com outros saberes, seus limites, suas possibilidades) demanda um grande esforço educacional, necessitando-se de uma divulgação científica interligada com a Educação Ambiental (EA) em sua vertente crítica. Os espaços educacionais que podem comportar práticas pedagógicas voltadas para a relação entre ciência e questões socioambientais são os mais variados.

\footnotetext{
${ }^{1}$ Universidade de São Paulo (USP-EACH). E-mails: gustmeyer@msn.com, guicmeyer@hotmail.com.
} 
Ao lado de instituições sociais de educação formal, por exemplo, existem outros núcleos de aprendizagem, as chamadas comunidades aprendentes; exemplos de espaços que abrigam uma educação dessa espécie são os museus.

Um museu possui particularidades importantes na realização de práticas educativas quando comparado com outros espaços educacionais, propiciando uma maior liberdade na seleção e organização de conteúdos e metodologias, ampliando possibilidades de multi, inter e transdisciplinaridade e contextualização, permitindo a livre circulação do público entre suas temáticas; mas mais importante que esses fatores, os museus possibilitam a realização daquele "diálogo de saberes" apregoado por Leff (2003), onde tanto exposições fixas como itinerantes podem apresentar conteúdos que envolvam outras formas de conhecimento e suas estratégias de apropriação da natureza, dentro de um espaço que abriga o conhecimento científico.

Partiu-se da hipótese que, os atuais museus de ciência, em suas exposições que tratam de temáticas socioambientais, buscam explicitar ao público visitante o caráter conceitual do tema tratado, ou seja, se busca expor o fato de forma científica, não se abordando fatores políticos, sociais ou éticos que existem no contexto do tema. Tal forma de comunicação e divulgação científica, apesar de importante, por fornecer bases científicas mínimas para que os indivíduos possam opinar sobre determinado assunto, pode vir a prejudicar uma formação cidadã mais ampla, capacitada a intervir em políticas públicas ou privadas e, principalmente, não fornece subsídios para se pensar em outros modelos de desenvolvimento, mais justos e equitativos. Deve-se pensar e discutir, portanto, como os temas ambientais ou socioambientais, em museus de ciência, podem ser geradores de discussões políticas mais amplas e, além disso, como tais temas podem servir como articuladores entre as áreas científicas em si com outras formas de saberes.

\section{Algumas considerações metodológicas}

Tendo como referenciais teóricos a comunicação e divulgação científica em museus, a ecologia de saberes, a crise cognitiva e a necessidade do diálogo de saberes, e a concepção da educação ambiental crítica, em um primeiro momento desta pesquisa buscou-se os atributos referentes aos métodos de comunicação e educação científica praticados nos museus de ciência atualmente, discutindo-se a educação ambiental exercida nesses espaços, dentro do contexto de tais métodos. Posteriormente, foram avaliadas as práticas de cunho socioambiental praticadas na Estação Ciência, museu de ciência existente no município de São Paulo. Por fim, com o intuito de discutir possibilidades de práxis de EA de vias críticas para os museus de ciência, foram analisadas as concepções e práticas de EA do Museu de Astronomia e Ciências Afins (MAST) e do museu de ciências da UNICAMP. 


\section{Museus de Ciência: origens e conceito}

Primeiramente, é necessário conceituar de forma mais clara o objeto de estudo deste trabalho, os museus de ciência, tendo em vista que estes possuem ramificações com características peculiares, tratando de temas distintos entre si e, portanto, não incorporando, em muitos casos, temáticas socioambientais neste contexto de atuação.

Segundo Gaspar (1993), o surgimento do interesse pela divulgação e comunicação científica, utilizando-se museus que trabalhassem de modo particular a ciência, começou entre os séculos XVII e XVIII; o ápice ocorreu devido à revolução industrial e através do impacto provocado pela Teoria da Evolução de Darwin, quando formalmente surgiram os museus de ciência e tecnologia e os museus de história natural. Posteriormente, pós II Guerra Mundial, surgiram os chamados centros de ciência, que, apesar de objetivarem também a educação científica, se diferenciavam dos modelos de museus de ciência concebidos até então, já que possuíam um caráter menos "histórico", ou seja, não possuíam interesses profundos na conservação e preservação de objetos e, sim, na construção de suas próprias exposições, de acordo com suas áreas de interesse, possuindo artefatos de maior interatividade. Assim, de forma a construir uma linha cronológica do surgimento e papel dos museus de ciência, pode-se dizer que eles se dividem basicamente em dois grupos: a categoria tradicional, com preocupações voltadas para a preservação do passado, ou como centros de ciência, com vistas ao presente e ao futuro.

Para este trabalho, o mais importante é que os centros de ciência possuem, além das características já destacadas, uma ligação maior com a realidade cotidiana e com a interface meio ambiente/sociedade, o que possibilita uma avaliação, por parte desta pesquisa, da EA tratada nestes espaços, suas limitações atuais e potencialidades futuras.

Assim, com vistas a uma padronização, quando tratar-se neste trabalho a respeito da relação entre EA e museus de ciência, se deve levar em conta, como referencial de características e atuação, os centros de ciência contemporâneos, como já destacado.

\section{Museus: Papéis e modelos de comunicação}

Como já dito anteriormente, o papel exercido pelos museus de ciência alterou-se muito ao longo do tempo, provocando, inclusive, distinções em seu interior. Delicado (2004) procurou sistematizar as principais funções dos museus de ciência em Portugal, deixando claro que os resultados são aplicáveis a outros museus de ciência espalhados pelo mundo. Assim, a autora procura elencar, através de análises documentais e de entrevistas, aquelas que seriam as principais funções dos museus de ciência: a promoção da cultura científica, a investigação, o apoio ao ensino, os serviços à comunidade, a preservação do patrimônio, a educação ambiental e o reforço da Identidade (local ou institucional). Nota-se o destaque especial dado ao fato da EA, tema 
deste trabalho, ser um dos papéis atuais dos museus de ciência, principalmente dos centros de ciência.

Naturalmente, todavia, sabe-se que o principal objetivo dos museus de ciência, deixado claro em sua denominação, é a promoção da cultura científica, a qual Delicado, define como sendo "a comunicação (unívoca ou bidirecional) entre o campo de produção da ciência e a esfera pública, podendo os conteúdos (conhecimentos, resultados, processos, controvérsias, descobertas, riscos, impactos sociais) e objetivos (econômicos, políticos, sociais, culturais, cívicos) dessa comunicação, serem muito diversificados" (2004, p.4).

Nessa lógica de raciocínio, pode-se dizer que, discussões mais profundas quanto às concepções e práticas de EA exercidas no espaço do museu, suas limitações, críticas e potencialidades, dependem primordialmente do entendimento histórico dos métodos comunicacionais e educacionais desenvolvidos e utilizados pelos museus de ciência, com o objetivo principal da comunicação e educação científica, tendo em vista que tais métodos empregados influenciarão diretamente os outros papéis dos museus de ciência, subsidiando as práticas de EA empregadas.

Segundo Navas (2008), existem quatro modelos de comunicação pública de $C$ \& $T$, considerados os principais: o modelo antigo ou de déficit, o modelo contextual, o modelo da experiência leiga e o modelo dialógico (modelo de participação pública). Atualmente, segundo a autora, estes modelos apresentados convivem muitas vezes no mesmo espaço, em um museu de ciência, por exemplo, existindo, todavia, um modelo que se mostra preponderante ou dominante em relação aos demais, que é o caso do modelo de déficit.

O modelo de déficit é o mais antigo dentre os quatro modelos, partindo de uma visão onde a ciência encontra-se desvinculada da sociedade no mundo moderno, existindo, portanto, um espaço a se preencher, já que o conhecimento científico não chega ao conhecimento do público. Neste modelo, portanto, assume-se uma visão simplista da ciência, tida como um corpo neutro de conhecimentos, onde os cientistas são autoridades no assunto e, aquilo que produzem, é tido como verdade absoluta, longe de sofrer interferências do contexto sociopolítico existente.

Valente assinala que "enquanto os museus de ciência (...) tradicionais (...) mostram dificuldade em comunicar uma perspectiva compreensiva do conhecimento científico atual, os centros de ciência apresentam a ciência sem antecedentes, fora do contexto cultural e fragmentada" (2005, p.55), privilegiando a apresentação de fenômenos naturais.

Dessa forma, tal discussão apresentada até aqui vem a corroborar uma parte da hipótese levantada, quanto ao fato dos centros de ciência atuais privilegiarem a apresentação do conteúdo científico em si, sem maiores discussões. No entanto, isto não é o cerne da questão deste trabalho, sendo necessário verificar como o uso preponderante do modelo de déficit pode 
limitar a EA praticada pelos centros de ciência e, mais do que isso, de que forma a EA pode potencializar o uso do espaço de um museu científico.

\section{Crise Ambiental, Educação Ambiental, e Museus de Ciência}

\section{Reflexões quanto à crise ambiental}

A questão ambiental emerge de maneira mais significativa e ampla a partir dos anos 1970, expressando a contradição entre o modelo de desenvolvimento dominante e a realidade socioambiental, pretendendo-se a conciliação da preservação ambiental com o desenvolvimento industrial (com bases técnico-científicas), dentro de um modo de produção capitalista. Tal visão instrumental e hegemônica impregna, portanto, a educação de forma geral, vista como a serviço do modo de produção capitalista e, portanto, opressora. Antes de adentrar-se, entretanto, na educação em si, é necessário que se vá mais a fundo nas origens da crise ambiental. Segundo Leff (2003), as raízes da crise ambiental são muito mais profundas, entendo-a como crise de civilização, crise do pensamento ocidental. Há, portanto, uma clara crítica à ciência e também à tecnologia associada a esta.

Tal paradigma científico materializa-se nas relações econômicas, alicerçando de maneira teórica e prática um modo de produção que modificou profundamente a relação dos seres humanos entre si e destes com a natureza: o modo de produção que nasceu com a Revolução Industrial, explorando o meio de modo cada vez mais intenso, de acordo com o advento e o aprimoramento das técnicas. É importante salientar que, neste contexto, "meio" deve ser entendido a partir da visão de Castro (2002), o qual já em 1972 caracterizava o "meio" de modo multidimensional, sem reducionismos, incluindo não somente o meio físico ou biológico, mas também o meio econômico e cultural.

Percebe-se, portanto, pelo que foi exposto até o momento, que é um erro atribuir as responsabilidades pelos problemas ambientais ao homem enquanto espécie genérica, devendo-se deslocar o foco para a dinâmica sociedade $x$ natureza e não ser humano x natureza, apesar das incoerências que caracterizam todas essas oposições, como será explicitado posteriormente. Nessa mesma linha, também se constitui um equívoco responsabilizar a todos pela degradação ambiental, dentro de uma sociedade marcada pela disparidade nas relações de poderes, onde a grande maioria dos indivíduos está imersa "na ação ingênua, mecânica e controlada ideológica e politicamente pelos 'opressores" (PITANO; NOAL, 2009, p.293).

Cabe relembrar e aprofundar, no entanto, que apesar de muitos problemas ambientais terem se materializado através do modo de produção dominante, foi a ciência e o método científico que subsidiaram teórica e filosoficamente tal modelo, como já dito, sendo assim, o cerne da questão ambiental encontra-se na forma do pensamento ocidental, em suas características e maneiras de enxergar a realidade complexa. 
Dentro desse contexto do pensamento ocidental, surge uma distinção importante para a maneira de como a sociedade se relaciona com a natureza, a distinção entre o mundo da natureza e o mundo da cultura. Segundo Carvalho (2005), é na filosofia dos antigos gregos onde se desenvolvem os argumentos teóricos que caracterizam tal distinção, resultando na definição hegemônica de natureza como oposta a de homem, de cultura e de história, e, portanto, vista como objeto de estudo.

Essas dicotomias são exemplos de uma das características marcantes do pensamento ocidental, a fragmentação histórica do saber com vistas à compreensão da realidade complexa. Desse modo, destacam-se duas abordagens mais gerais da questão ambiental no âmbito científico. Em uma dessas visões, geralmente oferecida pelas Ciências Humanas, é dada ênfase aos fatores histórico-sociais, em detrimento dos aspectos técnicos e naturais da questão ambiental; a outra visão, que não pode ser relacionada a uma área do conhecimento em específico, enfatiza as dimensões naturais e técnicas da questão ambiental, destacando-se os temas ecológicos. Dentre as duas abordagens, a visão técnica e naturalizante é aquela que tem prevalecido.

De maneira geral, portanto, o conceito de meio ambiente, multidimensional, incluindo os aspectos naturais e os resultantes das atividades humanas (resultado da interação de fatores biológicos, físicos, sociais, econômicos e culturais), é comumente confinado às suas dimensões naturais ou técnicas; tal conceito acaba sendo confundido com o de natureza, chegando-se a colocá-los como sinônimos.

Assim, a questão ambiental diz respeito ao modo como a sociedade se relaciona com a natureza - qualquer sociedade ou natureza - incluindo as relações dos seres humanos entre si; como destaca Moraes, baseado originalmente no marxismo, "a estruturação da sociedade define a relação dos indivíduos com a maior parte dos recursos naturais, ao normatizar as suas relações entre si" (2005, p. 75).

\section{Reflexões quanto a crise ambiental: conceitos de desenvolvimento}

Dentro do contexto de termos relacionados à questão ambiental, também a expressão "desenvolvimento sustentável", tido como o ideal a se alcançar em termos societários num contexto de crise ambiental, é marcado pela ambiguidade, abrangendo dois significados: um que inclui a dimensão política e ética e o outro que se refere unicamente ao gerenciamento adequado (ou sustentável) dos recursos naturais, sendo que, em ambos os casos, aposta-se no desenvolvimento do patamar tecnológico, necessário à superação da crise do capital.

O termo desenvolvimento pode ser entendido de três maneiras distintas, mas que muitas vezes se confundem. A primeira visão, mais frequente, é a de tratá-lo como sinônimo de crescimento econômico. Segundo Veiga (2005), até o início dos anos 60, essa forma de ver o desenvolvimento era a mais comum, visto que as nações consideradas mais desenvolvidas eram aquelas que

revista brasileira educação ambiental 
possuíam um melhor desempenho econômico, enquanto que os países de pior desempenho econômico permaneciam em um estágio de "subdesenvolvimento". A segunda visão de desenvolvimento é a de que ele é apenas uma ilusão, manipulação ideológica, quimera, estabelecendo uma simples equivalência entre desenvolvimento e riqueza. De certa forma, esta segunda visão também remete ao crescimento econômico. A terceira visão pode ser resumida em uma frase de Celso Furtado:

(...) o desenvolvimento se caracteriza pelo seu projeto social subjacente. Dispor de recursos para investir está longe de ser condição suficiente para preparar um melhor futuro para a massa da população. Mas quando o projeto social prioriza a efetiva melhoria das condições de vida dessa população, 0 crescimento se metamorfoseia em desenvolvimento (2004, p. 484).

Assim, a palavra "desenvolvimento" pode tanto ser associada a ideias positivas, no sentido qualitativo ou de incremento, como pode ser confundida com questões quantitativas de crescimento econômico; todavia, o grande cerne da questão da palavra "desenvolvimento" encontra-se no fato de qual tem sido, historicamente, o significado de "desenvolver", já que, muitas intervenções antrópicas que degradam recursos naturais e desrespeitam comunidades tradicionais, tem sido feitas em nome do "progresso" e do "desenvolvimento". Para Brugger (2004), o sentido de desenvolvimento hegemônico tem sido o de converter todos os padrões culturais em apenas um.

Está associada à palavra "desenvolvimento", portanto, um caráter evolucionista, distinguindo-se, na sociedade, fases infantis ou primitivas, fases de desenvolvimento e fases maduras. Assim, o falacioso objetivo de um futuro melhor sempre está em vista. Nesse sentido, Castro (2000), por exemplo, destaca que o subdesenvolvimento é uma forma de poluição humana, conseqüência do crescimento econômico de regiões mais ricas, não sendo, portanto, uma fase ou caminho para o desenvolvimento (em um sentido associado ao crescimento econômico), e sim um subproduto deste.

Já em relação à palavra "sustentável", está origina-se da Ecologia (ciência natural), sendo relacionada, geralmente, à natureza homeostática dos ecossistemas naturais, englobando, ainda, conceitos como o de "capacidade de suporte", por exemplo. O termo sustentabilidade também pode ser visto de três modos distintos. A primeira visão é a de que não existe dilema entre conservação ambiental e crescimento econômico. Essa hipótese é mais conhecida como "curva ambiental de Kuznets", que mostra que, apesar do crescimento econômico prejudicar o meio ambiente (em um sentido puramente físico ou biológico) até que certo nível de riqueza seja alcançado, após atingirse esse patamar, a tendência se inverteria, ou seja, o crescimento econômico auxiliaria na conservação ambiental (VEIGA, 2005). 
Em contrapartida a esse pensamento, está a relação entre economia e termodinâmica, tese de Nicholas Georgescu-Roegen. Baseado na segunda lei da termodinâmica (entropia), Georgescu-Roegen aponta que as atividades econômicas representam fluxos energéticos que são convertidos em formas de calor difusas, tornado tal energia inutilizável. Assim, em algum momento, segundo Georgescu, a humanidade deverá retrair o consumo dos produtos para que o desenvolvimento possa continuar a ocorrer. Dentro dessa vertente, encontra-se também Herman E. Daly, que possui uma visão ainda mais cética, em que só a "condição estacionária" pode evitar a decadência ecológica. Por fim, a terceira visão de sustentabilidade tenta avançar pelo "caminho do meio", entre as duas hipóteses tão opostas. No entanto, ainda é apenas uma tentativa.

Dessa forma, o adjetivo "sustentável" associado ao termo "desenvolvimento", assim como a questão ambiental em si, tem uma forte dimensão técnica naturalista, insuficiente para dar conta da complexidade inerente às relações entre sociedade e natureza. Neste padrão de soluções técnicas, a preservação de potenciais produtivos aparece como o principal critério de sustentabilidade do pensamento hegemônico, o que, apesar de ser uma condição necessária, não é o suficiente, agradando muito mais a grupos de poder em específico, do que a sociedade de maneira geral.

Questões sociais, éticas e ecológicas acabam, dessa forma, sendo relegadas a segundo plano, ou seja, esse padrão alternativo de desenvolvimento chamado sustentável acaba se tornando uma roupagem nova do padrão de desenvolvimento tradicional, utilizando-se de recursos técnicos no gerenciamento de recursos naturais tido como importantes para certos grupos hegemônicos. A conversão de padrões culturais, portanto, permanece, travestido de uma nova roupagem verde ou de uma dita responsabilidade ambiental.

Cabe destacar que, anteriormente ao surgimento do conceito de desenvolvimento sustentável e de sua difusão, o economista Ignacy Sachs apropriou-se do termo "ecodesenvolvimento", lançado por Maurice Strong em 1973, desenvolvendo-o conceitualmente e criando estratégias para alcançá-lo. O conceito de desenvolvimento sustentável é muitas vezes considerado uma versão evoluída e melhor lapidada da noção de ecodesenvolvimento; todavia, Layrargues (1997) destaca que, apesar das semelhanças nas ideias contidas nos termos, existem diferenças importantes.

De forma geral, o desenvolvimento sustentável e o ecodesenvolvimento possuem um fim em comum, atingir o patamar de sociedades sustentáveis; para este fim, no entanto, possuem estratégias diferenciadas. 0 desenvolvimento sustentável, como já dito, mantém a ideologia dominante, acreditando amplamente no desenvolvimento tecnológico e na busca da eliminação da pobreza nos países subdesenvolvidos (na busca da elevação do teto de consumo destes, e não na redução do consumo dos países ditos desenvolvidos) como estratégias para a "preservação ambiental". Já o ecodesenvolvimento, apesar de também reforçar a importância da tecnologia, 
prega o desenvolvimento tecnológico endógeno, respeitando necessidades socioculturais, e não a simples transferência de tecnologia exógena.

Nesse sentido, muitos autores sugerem a substituição do conceito de desenvolvimento sustentável pelo de sociedade sustentável, tendo em vista que o conceito de sociedade sustentável, em ideais convergentes com o pregado pelo ecodesenvolvimento, "permite a cada sociedade definir seus modelos de produção, consumo e bem-estar a partir de sua cultura, de sua história e de seu ambiente natural, abandonando a transposição imitativa de soluções padronizadas para contextos e realidades bastante diferenciadas" (LIMA, 1999: p.5). Contudo, talvez isso seja uma questão menor, no sentido que a manutenção do conceito de desenvolvimento sustentável depende muito mais do seu conteúdo e uso real, do que da forma em si.

Finalizando, cabe destacar que a importância deste capítulo, na discussão de teorias e ideologias que perpassam os diferentes modelos de desenvolvimento, deve-se a ausência da possibilidade deste tipo de debate no interior dos museus de ciência, dado o modo de EA preferencialmente praticado, como será apresentado posteriormente.

\section{Educação ambiental: contexto geral e vertentes}

Dentro desse contexto complexo relacionado à crise ambiental, surge a partir da década de 1970 a articulação entre educação e meio ambiente como uma das ações de enfrentamento de tal crise.

Pode-se dizer, inicialmente, que existe uma convergência de ideias sobre o que seria a EA e o que deveria ser a Educação no seu contexto amplo. Dessa forma, surge a primeira contradição da Educação com a adjetivação "ambiental", visto que ela nasce como sendo uma ramificação da Educação em si, voltada para a resolução dos problemas da sociedade referentes à degradação do ambiente. A EA nasce, portanto, dentro da lógica do pensamento ocidental, com a sua característica tecnicista de fragmentação dos saberes, concebida no interior do pensamento que está na raiz da crise ambiental.

Dessa maneira, o grande problema, no que tange uma EA desvinculada de uma Educação em sentido mais amplo, é que a EA acaba, na prática, promovendo a perpetuação do sistema vigente, sendo opressora, ou adestradora nas palavras de Brugger (2004), apesar da construção teórica da EA apontar para outras tendências. No entanto, cabe destacar que o grande problema está na base epistemológica e ética da educação em si, sendo esta uma educação ambiental ou não.

Portanto, ainda imerso no contexto colocado pelo trecho acima, Brugger (2004), enfatiza que talvez o mais coerente para o resgate dos aspectos epistemológicos e éticos da questão ambiental seja a revisão e o resgate dessas dimensões dentro do próprio conhecimento que construímos. 
Assim, as correntes de EA existentes possuem diferentes visões acerca da problemática ambiental, buscando alternativas de ação de acordo com suas concepções. De maneira geral e resumida, devido à forma de organização do conhecimento na sociedade (fragmentação da ciência), distinguem-se as duas tendências gerais já apresentadas neste trabalho: as propostas educacionais oferecidas pelas ciências humanas, com destaque para fatores históricos e sociais (EA crítica), e a tendência geral e predominante, que concentra sua abordagem quase que exclusivamente sob aspectos naturais e técnicos dos problemas ambientais (EA convencional).

Segundo Lima (2004), a chamada EA convencional tende a converter a complexidade da questão ambiental à singularidade de alguma de suas dimensões, agindo de forma reducionista, portanto. A problemática ambiental, complexa e multidimensional, acaba reduzida, assim, a questões de gerenciamento de recursos naturais (e humanos) escassos, a poluição, a destruição da camada de ozônio, entre outros temas, sendo associada a disciplinas do conhecimento já constituídas, incorporando conceitos e visões de mundo oriundas destas (como o conceito hegemônico de natureza), sem considerar a visão sistêmica da realidade necessária para o trato da crise ambiental.

A esse tipo de EA predominante, mesmo que disfarçadamente, em projetos, documentos oficiais, trabalhos e em espaços educacionais como um todo, pode-se qualificar como sendo uma espécie de adestramento ambiental, que Brugger define como sendo "uma instrução de caráter essencialmente técnico, fruto de uma visão de mundo cientificista e unidimensional" (2004: p. 12). Tal forma de educação ou instrução, também predominante nos museus de ciência, como será aprofundado posteriormente, é uma forma de adequação dos indivíduos ao sistema social vigente, uma forma de opressão, perpetuando uma estrutura social injusta. Normalmente, a fachada de um saber técnico oculta ou serve como argumento para uma decisão puramente política.

Tal visão parcial e reducionista, segundo Lima (2004), favorece uma compreensão despolitizada e alienada dos problemas ambientais, ocultando seus motivos políticos e confundindo a prioridade entre variáveis dependentes (causas) e independentes (efeitos). $O$ autor afirma também que a despolitização pode, inclusive, ser observada na banalização do uso das noções de cidadania e participação social nos discursos oficiais de EA, usandose tais conceitos no contexto do capitalismo, "ora como meios de ocultar as desigualdades sociais e de legitimar sua manutenção, ora como conquistas associadas ao consumo" (2004, p. 90).

Partindo de uma visão técnica, naturalizante e, portanto, reducionista, da questão ambiental, as ações propostas por esse tipo de educação adestradora tem seu conteúdo esvaziado, diagnosticando o problema socioambiental como um problema de comportamentos individuais, vendo a solução de forma paliativa e pontual, na mudança de comportamento dos indivíduos em sua relação com o ambiente. Não se questiona, assim, as causas profundas da crise ambiental, as resoluções dos problemas parecem simples, pautadas em

revista brasileira educação ambiental 
conhecimentos científicos neutros capazes de solucionar os problemas dentro da mesma lógica vigente.

Da mesma maneira, as soluções com base na correção de comportamentos individuais parecem querer responsabilizar a todos, de maneira igualitária, pelos problemas socioambientais, não se levando em consideração o desequilíbrio de poderes existente na sociedade, e a heterogeneidade que a compõe.

\section{Educação Ambiental e Museus de Ciência}

Dentro do contexto apresentado até o momento neste trabalho, a questão que permanece, portanto, diz respeito à quais características apresenta a EA que é tratada dentro dos museus de ciência. Para o trato desta problemática, é importante o resgate do modelo de comunicação pública da ciência que é predominante nos museus científicos, assim como suas características principais. O modelo de comunicação pública da ciência que prevalece nos museus de ciência é o modelo de déficit que, de maneira resumida, coloca a ciência como um corpo neutro de conhecimentos, ahistórica, sem quaisquer relações com a sociedade, não podendo ser influenciada, portanto, por questões sociais, políticas ou culturais. Percebe-se claramente, dessa maneira, nos atributos do modelo de déficit predominante, fortes relações com as características que marcam o chamado adestramento ambiental já destacado. Assim, a EA que é praticada nos museus de ciência possui características naturalizantes (ou conservacionistas) e técnicas, buscando mudanças comportamentais individuais, sem discussões éticas, políticas, culturais e históricas mais relevantes.

Além disso, a temática ambiental tende a ser compartimentada no interior dos museus científicos, seguindo a lógica geral que ramifica a educação em educação ambiental, associando-se o "ambiental" a disciplinas ou corpos científicos que tendem a ser considerados como aqueles que inerentemente são os mais adequados para abarcar os problemas socioambientais. Portanto, nos museus científicos a ciência tende a ser fragmentada em corpos científicos separados (física, biologia, Ciências da Terra, entre outros), e o trato da temática ambiental tende a ser associada a alguma dessas disciplinas, sem que haja uma maior transversalidade ou interdisciplinaridade, colocando-se os problemas socioambientais de forma desvinculada de outras dimensões importantes da realidade, reduzido ao trato de fenômenos científicos ou à soluções simplistas de caráter gerencial, sem que se aborde as causas reais dos problemas.

De modo a se colocar um exemplo de EA de caráter técnico e naturalizante dentro dos espaços museais, é pertinente a análise do projeto intitulado "O Planeta Terra e a Preservação Ambiental" (TEIXEIRA, 2007), desenvolvido para a Estação Ciência, museu científico localizado em São Paulo e inaugurado em 1987 pelo Conselho Nacional de Desenvolvimento Científico e Tecnológico- CNPq. 
O problema principal deste projeto deve-se a associação da temática ambiental somente a área da Geologia, compartimentando-a em certa disciplina, como destacado pelo fato de que o projeto visou ampliar a área de Geologia e Meio Ambiente da Estação Ciência (TEIXEIRA, 2007). Tal forma errônea de abordar a problemática ambiental acaba desencadeando em aspectos relacionados à um tipo de adestramento ambiental, mais do que uma educação ambiental.

As características "adestrantes" do projeto se fazem presentes por todo o seu conteúdo, a começar pela sua proposta principal, que é a de que todos tenham racionalidade no uso dos recursos naturais não renováveis e adotem posturas responsáveis em relação ao meio ambiente, em benefício das futuras gerações (TEIXEIRA, 2007). Observa-se explicitamente no trecho destacado uma visão reducionista da questão ambiental, associada ao simples gerenciamento técnico dos recursos naturais, assim como, percebe-se que mudanças de posturas comportamentais são incentivadas como a solução dos problemas socioambientais.

Logicamente, não se quer dizer neste trabalho que tais abordagens técnicas e naturalizantes, no trato da questão ambiental, não são importantes, todavia, reduzir-se a questão somente a este ponto, sem maiores problematizações, é uma forma de alienação e mesmo de opressão. Tais temas socioambientais poderiam ser geradores de discussões mais amplas, o que não está colocado como propósito do projeto destacado, por exemplo. Também não se quer dizer que a ciência não possui papel de extrema relevância no trato das problemáticas socioambientais, todavia, faz-se necessário que a ciência seja incluída em um contexto social, cultural e político mais amplo, assim como, deve-se se colocar a ciência em diálogo com outras formas de saberes.

É claro também, como já colocado anteriormente neste trabalho, que o modelo de déficit não é universal para todos os museus de ciência, existindo inúmeras experiências que se contrapõe a esse tipo de modelo predominante, buscando atividades educacionais inovadoras, as quais serão tratadas posteriormente.

\section{Educação Ambiental crítica e Museus de Ciência}

Apesar das críticas feitas nesta pesquisa, quanto à predominância, nos museus de ciência, de uma forma de EA de caráter técnico, naturalizante e ahistórica, existem exemplos de projetos interessantes desenvolvidos em alguns museus de ciência, os quais possuem como concepção e prática a EA de caráter crítico. Um exemplo de projeto inserido neste contexto encontra-se no Museu de Astronomia e Ciências Afins (MAST).

A EA crítica possui inúmeras premissas, oriundas da Teoria Crítica, e também está relacionada a outras noções contestatórias do modelo de sociedade preponderante. Guimarães e Vasconcellos (2006) destacam os elementos incorporados a ideia de EA crítica que concebem para a prática 
educativa do MAST, incluindo a necessidade do aumento do empoderamento da população, a leitura crítica da realidade para a ação, e a necessidade de cooperação entre as diversas instituições educativas, formais e não formais.

Assim, apresentada a concepção de EA existente no MAST, a principal prática educativa que deriva de tal concepção, segundo Guimarães e Vasconcellos (2006), é a ação denominada de "trilha ambiental", imersa em um contexto museal mais amplo, no qual, segundo os autores, "a partir dos ambientes educativos provocados pelos conteúdos das diferentes exposições e seus mediadores" (GUIMARÃES; VASCONCELLOS, 2006, p.170), pretende-se estimular, no público visitante, reflexões sobre os referenciais paradigmáticos da sociedade contemporânea e a visão de mundo prevalecente.

Resumidamente, pode-se considerar que a característica positiva na proposta pedagógica do MAST advém da explicitação de seu vínculo com a EA crítica, com alguns fundamentos desta concepção desdobrando-se na prática do projeto da Trilha Ambiental adotado pelo MAST, como, por exemplo, através da busca pelo trato da problemática ambiental de forma sistêmica, histórica, não linear, e com características não-naturalizantes, utilizando-se, de maneira integrada, outros elementos comunicacionais do espaço museal, que não somente seus objetos e exposições. Além disso, a proposta da Trilha Ambiental agrega a metodologia ou ideia dos temas geradores, a serem levantados e abordados através dos elementos de comunicação do museu de ciência.

Contudo, alguns fundamentos importantes da EA crítica não estão explicitados na proposta da Trilha Ambiental, como as questões relacionadas a noção de justiça ambiental e, principalmente, 0 questionamento da responsabilidade científica nas origens da problemática socioambiental, além da possibilidade de diálogos entre a ciência e outras formas de saberes. Assim, elementos importantes para a discussão das causas da crise ambiental acabam sendo marginalizados. Neste ponto, pode-se tratar a respeito do museu de ciências da UNICAMP, espaço museal localizado em Campinas, desenvolvido a partir de 2003, onde se nota a explicitação de outros fundamentos da EA crítica, alguns existentes também no espaço do MAST, e vice-versa.

A missão do museu de ciência da UNICAMP, apresentada em seu projeto conceitual, bem como suas práticas preliminares, demonstram as duas preocupações centrais para sua criação: a desmistificação da ciência como prática neutra e descontextualizada; e os desdobramentos da aplicação do método científico para o cotidiano, seus impactos (positivos ou negativos) e sua utilização para a legitimação de práticas políticas, econômicas e sociais.

Com relação as práticas do museu de ciência da UNICAMP, existem alguns projetos de especial relevância, como a "Oficina Desafio", onde levamse desafios tecnológicos até as escolas, propondo-se aos estudantes o desenvolvimento de soluções tecnológicas para alguns dos problemas reais apresentados nas atividades. 
Apesar de o projeto ser interessante, faz-se necessário que os desafios sejam bem trabalhados, abordando-os em um contexto mais amplo, que considere outros elementos além do elemento técnico, somente. Assim, se tais desafios propiciarem discussões ampliadas e reflexões críticas sobre a ciência, a sociedade e a tecnologia, como propõe a missão e os objetivos do museu de ciências da UNICAMP, tornam-se atividades de grande potencial, que, inclusive, podem abarcar a temática da tecnologia social.

Foram apresentados e analisados, de maneira resumida, os aspectos conceituais relacionados ao museu de ciências da UNICAMP, sendo também apresentada uma de suas práticas, a título de exemplo. Nota-se, através dos exemplos de concepções e práticas de EA constituintes do MAST e do museu de ciências da UNICAMP, que a práxis de uma EA de caráter crítico, em toda a sua complexidade pedagógica (que condiz com a complexidade da crise ambiental), é de grande dificuldade, tendo-se em vista que nem todos os fundamentos desta vertente de EA encontram-se presentes nos museus de ciência exemplificados. Todavia, percebe-se que os museus analisados possuem concepções e práticas interessantes que podem complementar-se.

Assim, dada a complexidade da crise ambiental, pedagogicamente torna-se difícil para os museus de ciência uma práxis de EA crítica, em todos os seus fundamentos, não sendo possível o apontamento de respostas fáceis, mesmo porque, estas não existem. No entanto, existem caminhos que podem e devem ser considerados pelos museus de ciência.

Primeiramente, com relação a aspectos internos, o museu de ciência deve possuir uma abordagem educacional que considere todos os seus elementos pedagógicos; deve-se dar destaque especial, é claro, para seus objetos e exposições, contudo, outros aspectos e espaços do museu devem ser considerados, principalmente, a formação sociopolítica (e não somente técnica) de seus educadores. Além disso, os museus de ciência devem procurar refletir e dialogar (entre si e com o público) sobre suas bases conceituais e práticas, procurando a incorporação de elementos que propiciem uma comunicação que vá além da mera transmissão de informações.

Todavia, no que tange uma educação ambiental verdadeiramente crítica, que discuta e questione o modelo de desenvolvimento hegemônico, somente essas considerações não são suficientes, sendo necessária, além de uma maior articulação entre os museus de ciência e outras instituições de educação (formais e não formais), sobretudo, uma maior relação dos museus de ciência entre si, para que estes possam dialogar e refletir sobre suas práxis de âmbito socioambiental.

Por fim, acrescenta-se às considerações tecidas anteriormente, a possibilidade, e talvez necessidade, que os museus de ciência tragam aspectos que envolvam pedagogicamente outras formas de saberes, além do científico. Sabe-se que esse não é um dos objetivos dos museus de ciência, visto que tal tarefa parece estar compartimentada a museus antropológicos ou de outras características. Todavia, não existe necessidade de tal fragmentação 
dos conhecimentos, sendo que a abordagem de outros saberes (indígenas, de populações tradicionais, entre outros) potencializaria o caráter crítico e questionador do museu de ciência.

\section{Considerações Finais}

A partir do modelo de déficit, predominantemente presente nos museus de ciência, de características a-históricas e de transmissão de conhecimentos, revela-se também nestes espaços educacionais uma educação ambiental de atributos tecnicistas, naturalizantes e reducionistas, pautada pela ação nas consequências e não nas causas da questão ambiental, com foco em mudanças de comportamento individuais, e, principalmente, despolitizando o debate acerca da problemática ambiental em sua complexidade e multidimensionalidade, não propiciando maiores diálogos com outras formas de saberes.

$\mathrm{Na}$ análise da Estação Ciência, por exemplo, em seu projeto intitulado "O Planeta Terra e a Preservação Ambiental", observou-se a prática da educação ambiental com todas as características descritas anteriormente, além do fato de que a temática ambiental está compartimentada na área da Geologia, reduzida a um debate estritamente técnico, apresentando, hegemonicamente, características das ciências naturais.

Assim, explicitadas e analisadas criticamente as características da educação ambiental prevalecentes nos museus de ciência, com suas consequentes dificuldades de abordar as problemáticas socioambientais em suas causas reais e profundas, aprofundou-se a discussão com relação a educação ambiental de caráter crítico, apresentando-se, suas características e relações com outras noções contra-hegemônicas, e também suas possibilidades de subsídio teórico e prático para os museus de ciência. Percebeu-se, através do estudo dos fundamentos que compõem a educação ambiental crítica, bem como das noções atreladas à tal vertente, que dificilmente os museus de ciência, vistos individualmente, conseguiriam abarcar o trato de toda a complexidade multicausal que envolve a crise ambiental, articulando questões que envolvem o pensamento ocidental, o modo de produção predominante, e a visão de natureza hegemônica.

Contudo, através da análise dos projetos desenvolvidos pelo Museu de Astronomia e Ciências Afins (MAST) e pelo museu de ciências da UNICAMP, avaliou-se a existência de esforços teóricos e práticos na busca de abordagens pedagógicas mais críticas no trato das problemáticas socioambientais, mesmo que, individualmente, tais museus de ciência não consigam acolher todos os fundamentos de uma educação ambiental de vias críticas.

Tais esforços dizem respeito ao olhar: sistêmico, não linear, histórico, e não naturalizante da problemática ambiental, além da crítica à ciência como prática neutra e a-histórica, questionando-se suas responsabilidades quando ocorrem, como desdobramento de seu processo de criação, impactos socioambientais (positivos e negativos).

Revbea, São Paulo, V. 9, N 1:70-86, 2014. 
A partir do que foi exposto, considera-se, portanto, que apesar das claras dificuldades existentes para a práxis de uma educação ambiental crítica nos museus de ciência, faz-se necessário que os fundamentos e elementos que compõem essa vertente da educação ambiental sejam continuamente almejados pelos museus de ciência, os quais devem estar em permanente diálogo, já que possuem concepções e práticas que se complementam na busca de uma análise crítica da questão ambiental. Além disso, os museus de ciência devem ter em vista, como possibilidade pedagógica, a abordagem de atributos relacionados a outras formas de saberes, com vistas a potencialização de seu caráter educador, no trato mais profundo da crise ambiental, incluindo a crise do pensamento ocidental e a busca de outros tipos de "pensamentos" ou conhecimentos, os quais não devem ficar segregados somente em museus específicos para tal fim.

\section{REFERÊNCIAS}

BRUGGER, P. Educação ou Adestramento ambiental? Florianópolis: Letras Contemporâneas, 2004.

CARVALHO, M.B. Natureza. In: MOTTA, M. (org.). Dicionário da Terra. Rio de Janeiro: Ed. Record, p. 338-341, 2005.

CASTRO, J. Subdesenvolvimento: causa primeira da poluição. Geographia, América do Norte, v.4, n.8, p. 95-98, 2002.

DELICADO, A. Para que servem os museus científicos? Funções e finalidades dos espaços de musealização da ciência. Disponível em: $<$ http://www.ces.uc.pt/lab2004/pdfs/AnaDelicado.pdf> Acesso em: agosto de 2011.

FURTADO, C. Os desafios da nova geração. Revista da Economia Política. São Paulo, v. 24, n. 4, p. 483-486, 2004.

GASPAR, A. Museus e centros de ciência- conceituação e proposta de um referencial teórico. Tese de doutorado apresentada à Faculdade de Educação - USP, $\quad 1993 . \quad$ Disponível em:<http://www.casadaciencia.ufri.br/Publicacoes/Dissertacoes/gaspartese.pdf > Acesso em: agosto de 2011.

GUIMARÃES, M.; VASCONCELLOS, M.M.N. Educação ambiental e educação em ciências: um esforço de aproximação em um museu de ciências - MAST. Ambiente \& educação, v. 11, p. 165-173, 2006.

LAYRARGUES, P.P. Do ecodesenvolvimento ao desenvolvimento sustentável: evolução de um conceito? Proposta, v.25, n.71, p. 5-10, 1997.

LEFF, E. Pensar a complexidade ambiental. In: LEFF, E. (org.). A complexidade ambiental. São Paulo: Cortez, 2003.

LIMA, G.F.C. Questão Ambiental e educação: contribuições para o debate. Ambiente \& Sociedade, Campinas, ano II, n.5, p. 135-153, 1999. 
LIMA, G.F.C. Educação, Emancipação e Sustentabilidade: em defesa de uma pedagogia libertadora para a educação ambiental. In: LAYRARGUES (org.). Identidades da educação ambiental brasileira. Brasília: MMA, 2004.

MORAES, A.C.R. Meio Ambiente e Ciências Humanas. São Paulo: Annablume, 2005.

NAVAS, A. M. Concepções de popularização da ciência e tecnologia no discurso político. Dissertação de mestrado apresentada a faculdade de educação.

em:<http://www.teses.usp.br/teses/disponiveis/48/48134/tde-24062008-

151543/pt-br.php > Acesso em: agosto de 2011.

PITANO, S.C.; NOAL, R.E. Horizontes de Diálogo em Educação Ambiental: Contribuições de Milton Santos, Jean-Jacques Rousseau e Paulo Freire. Educação em Revista, Belo Horizonte, v. 25, n.3, p. 283-298, 2008.

TEIXEIRA, W. O Planeta Terra e a preservação ambiental. Anais da X Reunión de La RED POP y IV TALLER "Ciencia, Comunicación y Sociedad", Costa Rica, 2007.

VALENTE, M.E. . O Museu de Ciência: espaço da história da ciência. Disponível em:<http://www.scielo.br/pdf/ciedu/v11n1/05.pdf> Acesso em: agosto de 2011.

VEIGA, J. E. Desenvolvimento Sustentável: O desafio do século XXI. Rio de Janeiro: Garamond, 2005. 